\title{
Persistent Infection with Rotavirus Vaccine Strain in Severe Combined Immunodeficiency (SCID) Child: Is Rotavirus Vaccination in SCID Children a Janus Face?
}

\author{
Maria Antonia De Francesco ${ }^{1, *}$, Giovanni Ianiro ${ }^{2}$, Marina Monini ${ }^{2} \oplus$, Cesare Vezzoli ${ }^{3}$, \\ Richard Fabian Schumacher ${ }^{4}$, Silvia Giliani ${ }^{5}$, Giovanni Lorenzin ${ }^{1}{ }^{\circledR}$, Francesca Gurrieri ${ }^{1}$ and \\ Arnaldo Caruso ${ }^{1}$ \\ 1 Institute of Microbiology, Department of Molecular and Translational Medicine, University of \\ Brescia-Spedali Civili, 25123 Brescia, Italy; giovanni.lorenzin@hotmail.it (G.L.); \\ francescagurrieri@me.com (F.G.); arnaldo.caruso@unibs.it (A.C.) \\ 2 Department of Food Safety, Nutrition and Veterinary Public Health, Istituto Superiore di Sanità, 00161 Rome, \\ Italy; giovanni.ianiro@iss.it (G.I.); marina.monini@iss.it (M.M.) \\ 3 Pediatric Intensive Care Unit, Children's Hospital, ASST-Spedali Civili, 25123 Brescia, Italy; \\ cesare.vezzoli@asst-spedalicivili.it \\ 4 Haemato-oncology and BMT Unit, Children's Hospital, ASST-Spedali Civili, 25123 Brescia, Italy; \\ fabian.schumacher@unibs.it \\ 5 A. Nocivelli Institute for Molecular Medicine, Department of Molecular and Translational Medicine, \\ University of Brescia, 25123 Brescia, Italy; silvia.giliani@unibs.it \\ * Correspondence: maria.defrancesco@unibs.it; Tel.: +39-030-3995860
}

Received: 29 October 2019; Accepted: 14 November 2019; Published: 16 November 2019

\begin{abstract}
We report the first case, to our knowledge, in Italy, of a severe combined immunodeficiency patient with a persistent rotavirus infection due to a vaccine derived strain. Rotavirus was detected by enzyme immunoassays and RT-PCR in stool specimens for five months. The persistent infection was resolved after complete immune reconstitution achieved by hematopoietic stem cell transplantation. This case underlines the importance of neonatal SCID_screening.
\end{abstract}

Keywords: SCID; vaccination; rotavirus; transplantation

\section{Case}

Severe combined immunodeficiency (SCID) includes inherited diseases with an impairment of $\mathrm{T}$ cell development, often associated with profound defects of $\mathrm{B}$ and/or NK cell differentiation. These genetic defects lead to severe and repeated infections by opportunistic microorganisms, to autoimmunity and neoplasies [1]. Clinical treatment is necessary to prevent severe life-threatening diseases and is based on hematopoietic stem cell transplantation or gene therapy when available [2].

Rotavirus infection is responsible for severe acute gastroenteritis and for half a million deaths a year, in children aged $<5$ years, especially in low and middle-income countries. For this reason, in 2009, the World Health Organization (WHO) recommended a rotavirus vaccination in all national immunization programs. Currently two live oral vaccines are licensed in Italy: RotaTeq, composed of five various human-bovine reasserting rotavirus strains (MercK) and Rotarix, a monovalent vaccine (GlaxoSmithKline). Rotavirus vaccination has been strongly recommended since 2017 for all infants between the age of six and twelve weeks (first dose). 
Infants with severe combined immunodeficiency, have severe side effects after the administration of live vaccines such as BCG (Bacillus Calmette-Guérin), measles, mumps, rubella (MMR) and varicella [3].

Also, for the rotavirus vaccination, a general concern is being raised about its safety in SCID patients, who develop severe clinical symptoms that require hospitalization. This was witnessed by different cases reported first in the United States [4-6] and in Australia [7], then in Europe (Germany and UK) [8,9], and more recently also in Japan [10]. This is one of the reasons, programmes of neonatal screening for SCID were recently introduced nation-wide in the USA [11] and just a year ago also in the Italian region of Tuscany.

Our patient was a full-term Italian female infant who was born without complications and to unrelated parents. According to the Italian routine childhood vaccination schedule, she received the first dose of Rotarix at 3 months of age and the second dose a month later. Though no immediate adverse effects were observed, she developed persistent severe diarrhoea and was hospitalized 10 weeks later for fever, failure to thrive, and severe hypotonia. A few days later, after severe lymphopenia and a life-threatening pneumonia triggered a suspicion of SCID, she was transferred to the paediatric intensive care in our hospital.

Bronchoalveolar lavage was positive for Pneumocystis jiroveci which was successfully treated with intravenous high-dose trimethoprim-sulfamethoxazole. Rotavirus was detected in stool specimen by enzymatic immunoassay, but no other enteric viruses or pathogenic bacteria were found. Diarrhoea and positive rotavirus stool specimens lasted for five months until the age of 11 months.

Given the severe lymphopenia (absolute lymphocyte count 80 cells $/ \mathrm{mm}^{3}$ ), subpopulations were analyzed and the results are shown in the Table 1. Immunoglobulin levels were below the detection limits. TRECS and T cell proliferative response to mitogens were completely absent completing the picture of T-B-NK+SCID (Table 1) Next generation sequencing allowed to detect the homozygous mutation c.G2210A:p.R737H in the recombination activating gene 1 (RAG1).

Table 1. Immunological characteristics of the severe combined immunodeficiency (SCID) patient.

\begin{tabular}{lc}
\hline Absolute Cell Counts & 80 Cells/mL \\
\hline Lymphocyte subpopulations & $\%$ \\
(age corrected normal \% range) & 1.9 \\
CD3+ T cells (52-83) & 1 \\
CD4+ T cells (31-58) & 0.9 \\
CD8+T cells (16-40) & 0 \\
CD19+ B cells (5-18) & 94 \\
CD16+56+NK cells (5-27) & T-B-NK+ \\
Immunophenotype & RAG1 \\
Gene defect & g/L \\
Serum Immunoglobulins & $<35$ \\
(age corrected normal range) & $<5.25$ \\
IgG (270-1100) & $<7.83$ \\
IgM (20-170) & PHA- \\
IgA (110-115) & T cell proliferation
\end{tabular}

To characterize this rotavirus infection, we investigated ten stool samples collected at different time intervals during the next five months.

Total viral RNA was extracted using the QIAmp Viral RNA Mini Kit (Qiagen, Monza Italy) from a $10 \%(\mathrm{w} / \mathrm{v})$ faecal suspension, following the manufacturers' instructions. Viral RNA was subjected to reverse transcriptase PCR (RT-PCR) of genes 9 and 4, encoding the outer capsid protein (VP7) and the viral hemagglutinin (VP4), respectively. The amplification was performed by using the forward primer Beg9 (5'-GGCTTTAAAAGAGAGAATTTCCGTCTGG-3') and the reverse primer End9 (5'-GGTCACATCATACAATTCTAATCTAAG-3') for VP7, and by using 
the forward primer Con3 (5'-TGGCTTCGCCATTTTATAGACA- $\left.3^{\prime}\right)$ and the reverse primer Con2 (5'-ATTTCGGACCATTTATAACC-3') for VP4 [12,13]. Genotyping of VP7 (G-type) and VP4 (P-[type]) was performed following European standardized protocols [14], and revealed the G1P [8] genotype for $9 / 10$ samples. The last sample collected was rotavirus negative in both the immune-enzymatic screening test and the PCR test (genotyping and sequencing), underlining the viral clearance of the patient. The RT-PCR amplicons of VP7 and VP4 (VP8* hypervariable region) were subjected to Sanger nucleotide sequencing, revealing the highest nucleotide sequence identities (nt id.) with the vaccine strain RVA/Vaccine/USA/Rotarix-A41CB052A/1988/G1P [8] (included in the Rotarix vaccine composition) for both VP7 (nt id. Ranging between $99.46 \%$ and $99.58 \%$ ) and VP4 (nt id. Ranging between $99.36 \%$ and $99.52 \%$ ). On the other hand, low nucleotide sequence identities were observed with respect to wild type G1P [8] strains circulating in Italy and with respect to the rotavirus strains included in the Rotateq vaccine composition. Sequences obtained were submitted to GenBank under the following accession numbers: MN549964 to MN549981.

The deduced amino acid sequences revealed four substitutions for VP7 (E73K, E149G/A, M202T, and N238S) with respect to the Rotarix viral variant. Two out of four substitutions (positions 149 and 238) were located in VP7 antigenic sites [15].

Also, for VP4, four amino acid substitutions were observed (T73A, Y152S, F167L, and P234S) with respect to Rotarix. None of the substitutions were included in any viral antigenic epitope [16].

At 10 months of age, the patient underwent transplant of bone marrow from a matched unrelated donor after reduced-intensity conditioning (fludarabine, busulfan and anti-thymocyte globulin). She received graft-versus-host disease prophylaxis with Cyclosporine and Mycophenolate Mofetil. Rotavirus could be detected in stool specimen for another 3 weeks thereafter; however, it cleared a week later after successful T-cell engraftment (300 CD3+ cells). Shortly thereafter, the patient was discharged from the transplant unit in good general conditions.

This case is the first reported in Italy. It reinforces the concept that live rotavirus vaccination in SCID patients can cause severe clinical symptoms such as diarrhoea, weight loss and a long viral persistence as demonstrated by the detection of rotavirus in multiple stool samples over 5 months; this suggests a continuous viral replication with a total clearance obtained only after successful immune reconstitution.

\section{Conclusions}

Due to the fact that the timing of the first dose of rotavirus vaccination is scheduled in children aged between six weeks and three months (it might trigger intussusception thereafter) and congenital immune deficiency is often still undiagnosed at that time, we suggest general newborn screening should be introduced as soon as possible. However, in its absence, clinicians should be particularly careful about clinical symptoms potentially related to SCID, such as failure to thrive and persistent or recurrent infections, in order to avoid the administration of rotavirus vaccine in this particular category of patients. Furthermore, persistent rotavirus infection in a vaccinated child should always trigger an immunologic work-up.

Therefore, while rotavirus vaccination constitutes a risk for infants born with SCID, it is safe for the general population (a different side of the same coin-'a Janus face') preventing more than $80 \%$ of severe cases of rotavirus diarrhea in countries with low death rates [17].

Author Contributions: M.A.D.F. wrote the manuscript; G.I. and M.M. performed molecular analysis and participated in the drafting of the manuscript; S.G. did the SCID mutation analysis; R.F.S. and C.V. were directly involved in the patient care and participated in the drafting and critical revision of the manuscript; G.L. and F.G. performed microbiological analysis; A.C. participated in the critical revision of the manuscript. M.A.D.F., G.I., M.M., S.G., R.F.S., C.V., G.L., F.G., and A.C. approved the final version.

Funding: This research received no external funding.

Acknowledgments: The Authors thank Antonella Surace for reviewing the paper for English language.

Conflicts of Interest: The authors declare no conflict of interest. 
Ethical Statement: Written consent was obtained from patient's parents for the publication of this case report.

\section{References}

1. Picard, C.; Al-Herz, W.; Bousfiha, A.; Casanova, J.-L.; Chatila, T.; Conley, M.E.; Cunningham-Rundles, C.; Etzioni, A.; Holland, S.M.; Klein, C.; et al. Primary immunodeficiency diseases: An update on the classification from the International Union of Immunological Societies Expert Committee for Primary Immunodeficiency 2015. J. Clin. Immunol. 2015, 35, 696-726. [CrossRef] [PubMed]

2. Buckley, R.H.; Schiff, S.E.; Schiff, R.I.; Markert, L.; Williams, L.W.; Roberts, J.L.; Myers, L.A.; Ward, F.E. Hematopoietic stem-cell transplantation for the treatment of severe combined immunodeficiency. N. Engl. J. Med. 1999, 340, 508-516. [CrossRef] [PubMed]

3. American Academy of Pediatrics. Red Book: 2018 Report of the Committee on Infectious Diseases, 31st ed.; Kimberlin, D.W., Brady, M.T., Jackson, M.A., Lomg, S.S., Eds.; American Academy of Pediatrics: Elk Grove Village, IL, USA, 2018; pp. 72-86.

4. Patel, N.C.; Hertel, P.M.; Estes, M.K.; De La Morena, M.; Petru, A.M.; Noroski, L.M.; Revell, P.A.; Hanson, I.C.; Paul, M.E.; Rosenblatt, H.M.; et al. Vaccine-acquired rotavirus in infants with severe combined immunodeficiency. N. Engl. J. Med. 2010, 362, 314-319. [CrossRef] [PubMed]

5. Kaplon, J.; Cros, G.; Ambert-Balay, K.; Leruez-Ville, M.; Chomton, M.; Fremy, C.; Pothier, P.; Blanche, S. Rotavirus vaccine virus shedding, viremia, and clearance in infants with severe combined immune deficiency. Pediatr. Infect. Dis. J. 2015, 34, 326-328. [CrossRef] [PubMed]

6. Bakare, N.; Menschik, D.; Tiernan, R.; Hua, W.; Martin, D. Severe combined immunodeficiency (SCID) and rotavirus vaccination: Reports to the Vaccine Adverse Events Reporting System (VAERS). Vaccine 2010, 28, 6609-6612. [CrossRef] [PubMed]

7. Werther, R.L.; Crawford, N.W.; Boniface, K.; Kirkwood, C.D.; Smart, J.M. Rotavirus vaccine induced diarrhea in a child with severe combined immune deficiency. J. Allergy Clin. Immunol. 2009, 124, 600. [CrossRef] [PubMed]

8. Klinkenberg, D.; Blohm, M.; Hoehne, M.; Mas Marques, A.; Malecki, M.; Schildgen, V.; Schneppenheim, R.; Müller, I.; Schildgen, O.; Kobbe, R. Risk of rotavirus vaccination for children with SCID. Pediatr. Infect. Dis. J. 2015, 34, 114-115. [CrossRef] [PubMed]

9. Morillo-Gutierrez, B.; Worth, A.; Valappil, M.; Gasper, H.B.; Gennery, A.R. Chronic infection with rotavirus vaccine strains in UK children with severe combined immunodeficiency. Pediatr. Infect. Dis. J. 2015, 34, 1040-1041. [CrossRef] [PubMed]

10. Yoshikawa, T.; Ihira, M.; Higashimoto, Y.; Hattori, F.; Miura, H.; Sugata, K.; Komoto, S.; Taniguchi, K.; Iguchi, A.; Yamada, M.; et al. Persistent sistemic rotavirus vaccine infection in a child with X-linked severe combined immunodeficiency. J. Med. Virol. 2019, 91, 1008-1013. [CrossRef] [PubMed]

11. Kwan, A.; Abraham, R.S.; Currier, R.; Brower, A.; Andruszewski, K.; Abbott, J.K.; Baker, M.; Ballow, M.; Bartoshesky, L.E.; Bonilla, F.A.; et al. Newborn screening for severe combined immunodeficiency in 11 screening programs in the United States. JAMA 2014, 312, 729-738. [CrossRef] [PubMed]

12. Gentsch, J.R.; Glass, R.I.; Woods, P.; Gouvea, V.; Gorziglia, M.; Flores, J.; Das, B.K.; Bhan, M.K. Identification of group A rotavirus gene 4 types by polymerase chain reaction. J. Clin. Microbiol. 1992, 30, 1365-1373. [PubMed]

13. Gouvea, V.; Glass, R.I.; Woods, P.; Taniguchi, K.; Clark, H.F.; Forrester, B.; Fang, Z.Y. Polymerase chain reaction amplification and typing of rotavirus nucleic acid from stool specimens. J. Clin. Microbiol. 1990, 28, 276-282. [PubMed]

14. Aoki, S.T.; Settembre, E.C.; Trask, S.D.; Greenberg, H.B.; Harrison, S.C.; Dormitzer, P.R. Structure of rotavirus outer-layer protein VP7 bound with a neutralizing Fab. Science 2009, 324, 1444-1447. [CrossRef] [PubMed]

15. Eurorotanet. Available online: https://www.Eurorotanet.com/ (accessed on 10 October 2019).

16. Dormitzer, P.R.; Sun, Z.Y.; Wagner, G.; Harrison, S.C. The rhesus rotavirus VP4 sialic acid binding domain has a galectin fold with a novel carbohydrate-binding site. EMBO J. 2002, 21, 885-897. [CrossRef] [PubMed]

17. Soares-Weiser, K.; Bergman, H.; Henschke, N.; Pitan, F.; Cunliffe, N. Vaccines for preventing rotavirus diarrhoea: Vaccines in use. Cochrane Database Syst. Rev. 2019, 3, CD008521. [PubMed]

(C) 2019 by the authors. Licensee MDPI, Basel, Switzerland. This article is an open access article distributed under the terms and conditions of the Creative Commons Attribution (CC BY) license (http://creativecommons.org/licenses/by/4.0/). 